\title{
DEPÓSITOS DE ALEXANDRITA DE MALACACHETA, MINAS GERAIS*
}

\author{
Márcio Silva Basílio ${ }^{1,2}$, Antônio Carlos Pedrosa-Soares ${ }^{3}$; Hanna Jordt-Evangelista ${ }^{1}$
}

\begin{abstract}
Since 1975, alexandrite $\left[\mathrm{Be}\left(\mathrm{Al}_{2-\mathrm{x}} \mathrm{Cr}_{\mathrm{x}}\right)_{2} \mathrm{O}_{4}\right]$, the chromium-bearing crysoberyl variety, has been exploited from alluvial and paleo-alluvial deposits in the Malacacheta region. The alluvial deposits consist of resedimented gravel along the present drainage streams. The paleo-alluvial deposits are richer in alexandrite, and show well-developed soil horizons covering the alexandrite-bearing gravel layer. Alexandrite grains show angular shapes with very sharp edges, suggesting transport for short distances. The country rocks are quartz-mica schist and peraluminous mica schist (Salinas Formation), covered by alternating mica schist and quartzite layers (Capelinha Formation). Both formations are of Neoproterozoic age. They host tectonic slabs of metaultramafic rocks, and are cut by intrusive granites of Cambrian age. No alexandrite-bearing rock has been found in the area, probably due to the intense tropical weathering. However, some of the mapped rocks are sources for $\mathrm{Be}$ (granites), $\mathrm{Cr}$ (metaultramafics) and $\mathrm{Al}$ (peraluminous schists), the essential elements for alexandrite crystallization. We suggest a metasomatic system of Cambrian age for alexandrite genesis in the area, involving the interaction of granite-related Be-rich fluids with metaultramafic rocks and peraluminous schists.
\end{abstract}

\section{INTRODUÇÃO}

Alexandrita, uma das mais raras e valiosas gemas do mundo, é a variedade cromífera do crisoberilo $\left(\mathrm{BeAl}_{2} \mathrm{O}_{4}\right)$. $\mathrm{O}$ efeito alexandrita se manifesta pela mudança de cor, em função do tipo de iluminação, que passa de verde intenso, sob luz do sol, para violeta ou vermelho framboesa, sob luz incandescente(White et al. 1967).

A substituição de parte do $\mathrm{Al}^{+3}$ por $\mathrm{Cr}^{+3}$, representada na fórmula $\left[\mathrm{Be}\left(\mathrm{Al}_{2-\mathrm{x}} \mathrm{Cr}_{\mathrm{x}}\right)_{2} \mathrm{O}_{4}\right]$, é a causa do efeito alexandrita. $\mathrm{O}$ conteúdo de cromo substituindo o alumínio pode variar dentro de limites relativamente amplos $(0,03 \%$ a $1,5 \%)$, sendo a presença do cromo o fator determinante da cor e da mudança de cor na alexandrita (Schmetzer et al. 1980, Gübelin e Schmetzer 1982, Pinheiro et al. 2000).

No Brasil, a alexandrita é explorada principalmente em Minas Gerais, nas regiões de Itabira-Nova Era e Malacacheta-Setubinha, sendo também encontrada em pequenas ocorrências no Espírito Santo e Bahia (Cassedanne e Baptista 1984, Pinto e Pedrosa-Soares 2001).

A descoberta de alexandrita em Malacacheta ocorreu em 1975, após a identificação de pequenas pedras verdes contidas no barro trazido do Córrego do Fogo (Fig. 1). Logo que estas gemas foram classificadas como alexandrita de alta qualidade, teve início um grande fluxo de garimpeiros que chegaram a totalizar 5000 homens acampados às margens do Córrego do Fogo e ribeirões Soturno e Setubinha.

A atividade garimpeira na região teve seu pico entre os anos de 1975 e 1987. Durante aqueles 12 anos foram produzidos cerca de $2 \mathrm{~kg}$ de alexandrita de muito boa qualidade (Proctor 1988). Em 1985 foi descoberto um cristal pesando 14,6 g no Ribeirão Soturno que, depois de lapidado, gerou um cabochão de 18,5 ct, considerado uma das mais raras e finas alexandritas olho-de-gato do mundo. A partir de 1987, a produção declinou muito. Em 1998, cerca de 100 garimpeiros ainda trabalhavam nos aluviões, mas a produção era muito pequena, não superando poucos quilates de gema de boa qualidade por ano.

\section{ENQUADRAMENTO GEOLÓGICO}

O Distrito Gemológico de Malacacheta localiza-se à cerca de $30 \mathrm{~km}$ ao norte da cidade homônima. $\mathrm{O}$ intenso intemperismo tropical transformou as rochas da área em extensos e profundos solos lateríticos com exposições periódicas de saprólito. Quando ocorrem, as exposições de rochas frescas situam-se ao longo de drenagens, cortes de estrada e escarpas íngremes.

O Distrito Gemológico de Malacacheta situa-se em terreno metamórfico de fácies anfibolito, intrudido por granitos, do domínio tectônico interno da Faixa Araçuaí (Pedrosa-Soares e Wiedemann-Leonardos 2000). As unidades estratigráficas da área estudada estão representadas na Figura 1.

O embasamento, de idade arqueana a paleoproterozóica, retrabalhado no Ciclo Brasiliano, é constituído predominantemente por biotita gnaisse bandado do Complexo Guanhães (Pedrosa-Soares et al. 1994). Sobre ele repousam as unidades que ocupam a maior parte da área, denominadas formações Salinas e Capelinha (Pedrosa-Soares 1995, Guimarães e GrossiSad 1997, Voll e Pimenta 1997). 
A Formação Salinas é composta predominantemente por quartzo-mica xisto granatífero e xisto peraluminoso rico em almandina e sillimanita fibrosa, com intercalações de rochas cálcio-silicáticas. Os xistos são mais ricos em biotita que moscovita. Seixos e matacões de formações ferríferas bandadas (tipos óxido e silicato) e de ortoanfibolitos são frequentes nos terrenos desta formação, na área estudada.

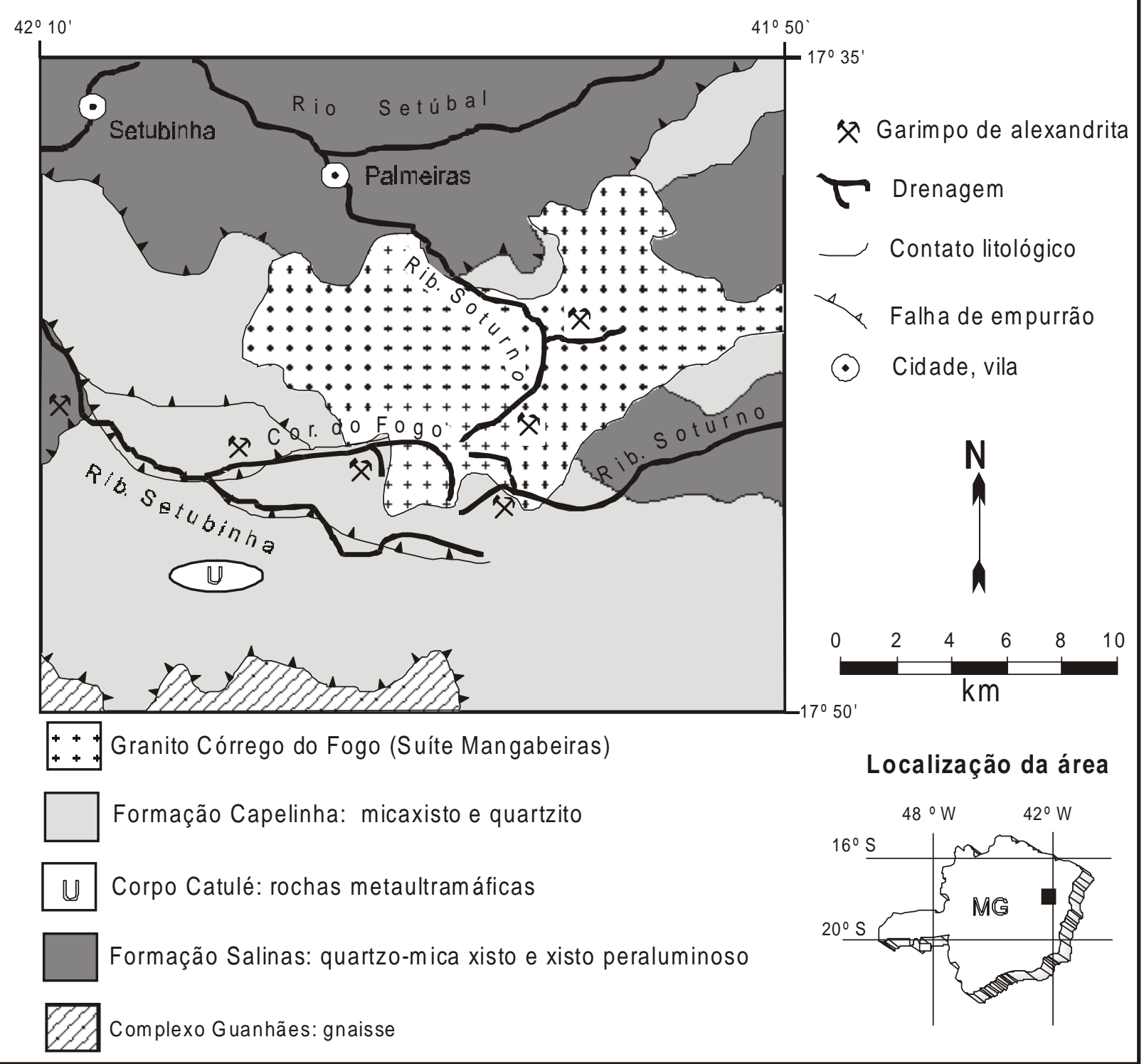

Figura 1: Mapa geológico simplificado da área garimpeira do Córrego do Fogo-Setubinha, no Distrito Gemológico de Malacacheta (adaptado de Voll \& Pimenta, 1997).

Figure 1: Simplified geologic map of the Córrego do Fogo-Setubinha area, Malacacheta Gemologic District (after Voll \& Pimenta, 1997).

A Formação Capelinha consiste em uma sucessão basal de camadas alternadas de micaxisto, grafita xisto e protoquartzito, coberta por espesso pacote de ortoquartzito. O micaxisto é rico em moscovita, granada e sillimanita fibrosa. O protoquartzito contém moscovita e/ou feldspato e/ou sillimanita. Veios quartzofeldspáticos com textura pegmatítica são comuns nas camadas ricas em moscovita. Parte destes veios parece ter origem anatética e parte parece estar relacionada às intrusões graníticas.
Corpos de rochas metaultramáficas ocorrem tectonicamente alojados nestas formações. $\mathrm{O}$ maior deles, denominado Corpo Catulé (Fig. 1), é constituído de tremolita-talco xisto com remanescentes de peridotito mostrando foliação milonítica. Espessos veios de diopsídio e quartzo, de granulação grossa, ocorrem associados a este corpo e foram garimpados para explotação dos belos cristais euédricos de diopsídio.

Um granito intrusivo ocupa a porção central da área (Fig. 1). Trata-se de granito homogêneo, a duas micas, 
no qual a biotita predomina sobre a moscovita e a granada ocorre como acessório frequente. A orientação por fluxo ígneo verificada nas bordas do corpo desaparece no seu interior. Roof-pendants e xenólitos de rochas encaixantes são frequentes nos maciços graníticos. Os atributos mineralógicos e geoquímicos evidenciam que o Granito Córrego do Fogo é do tipo $\mathrm{S}$, peraluminoso, alcalino-potássico e pós-colisional (Basílio, 1999).

Zircões desta intrusão foram separados para datação pelo método $\mathrm{Pb} / \mathrm{Pb}$ (evaporação) e agruparam-se em duas famílias. A família de zircões arredondados e corroídos, e cor amarelo claro a escuro, forneceu a idade de $2585 \pm 19 \mathrm{Ma}$. Esta idade indica que fonte arqueana forneceu zircões para os metassedimentos que sofreram fusão parcial para gerar o granito.

A família de zircões euédricos, límpidos, de prisma longo, forneceu a idade de $537 \pm 8$ Ma. Esta é a idade de cristalização do Granito Córrego do Fogo, em perfeita concordância com sua assinatura pós-colisional (Basílio 1999). Regionalmente, o Granito Córrego do Fogo pertence à Suíte G4, uma das suítes graníticas originadas durante o estágio de colapso orogênico póscolisional da Faixa Araçuaí (Pedrosa-Soares e Wiedemann-Leonardos, 2000).

Os pegmatitos encontrados na área estudada são veios relativamente pequenos, cuja espessura máxima está em torno de $3 \mathrm{~m}$. Quartzo, feldspato potássico macropertítico e moscovita são seus minerais essenciais, enquanto berilo e schorlita podem ocorrer como acessórios. Há pegmatitos que são claramente derivados do Granito do Córrego do Fogo, assim como há veios que são anatéticos. Em qualquer dos casos, são pegmatitos pobres em gemas que, eventualmente, produzem água-marinha. Cristais de rubelita ocorrem nos aluviões e provavelmente são oriundos dos pegmatitos. Não se tem notícia de alexandrita que tenha sido extraída dos pegmatitos da área.

\section{A ALEXANDRITA}

A alexandrita de Malacacheta apresenta-se como grãos milimétricos, mas raramente atinge alguns centímetros. Os grãos são angulosos e de arestas agudas. Faces cristalinas preservadas praticamente inexistem, devido ao intenso fraturamento. Estas características evidenciam transporte por distâncias curtas.

As cores da alexandrita de Malacacheta variam do verde ao azul (conhecida comercialmente como "azul pavão"), mas pode ocorrer nítido tricroísmo, variando entre azul, verde intenso e verde amarelado.

A presença do cromo, identificado por microssonda eletrônica, em substituição a parte do alumínio, está intimamente relacionada à característica mudança de cor, que se dá de verde ou azul em luz natural, para vermelho framboesa ou violeta sob luz incandescente. Os teores de cromo podem variar desde $0,3 \%$ a $1,2 \%$ (Basílio, 1999; Pinheiro et al., 2000).
Inclusões de talco, antofilita e actinolita-tremolita, minerais comuns na rochas ultramáficas da área, foram identificadas em grãos de alexandrita do Córrego do Fogo (Henn, 1987). Basílio (1999) também verificou a presença de inclusões cristalinas, na forma de um mineral fibroso (actinolita?) e um mineral placóide hexagonal (biotita?).

\section{DESCRIÇÃO DOS DEPÓSITOS}

Desde 1975 a alexandrita tem sido extraída apenas de depósitos aluvionares no Distrito de Malacacheta. É ainda desconhecida a rocha na qual os cristais de alexandrita se cristalizaram (Basílio, 1999).

Os depósitos mais ricos encontram-se ao longo de apenas dois cursos d'água: o Córrego do Fogo e o Ribeirão Soturno. Nos ribeirões Santana e Setubinha existem aluviões relativamente pobres em alexandrita. O Ribeirão Setubinha recebe as águas do Córrego do Fogo (Fig. 1).

Três superfícies erosivas foram identificadas na região de Malacacheta por Guimarães e Grossi-Sad (1997). A superfície mais antiga, representada por chapadas, possui altitudes em torno de $1200 \mathrm{~m}$. As chapadas são suportadas por quartzito da Formação Capelinha ou xisto da Formação Salinas.

A segunda superfície tem altitudes em torno de 900 m e suas drenagens mostram vales estreitos e de margens abruptas, como ocorre com o Ribeirão Setubinha. Este e outros cursos que se estabeleceram no segundo ciclo erosivo parecem ter sido herdados do primeiro ciclo. Estes cursos escavaram seus canais na primeira superfície e, persistindo em sua ação erosiva, adquiriram meandros que foram realçados durante o segundo ciclo.

A superfície erosiva mais recente é resultado do rebaixamento do nível de base local. Como evidência da erosão provocada por este rebaixamento observa-se a presença de paleoalúvios em cotas imediatamente superiores aos cursos d'água atuais e a reincisão dos aluviões atuais por estes mesmos cursos.

Nestes compartimentos do relevo foram identificados três tipos de depósitos secundários de alexandrita, a saber: depósitos em paleoalúvios, depósitos em alúvios recentes e depósitos em tálus.

Os depósitos paleoaluvionares estão presentes em grande parte da calha do Ribeirão Setubinha, nos trechos onde este corre mais encaixado, desde a foz do Córrego do Fogo até cerca de $5 \mathrm{~km}$ antes da cidade de Setubinha (Fig. 1).

Os depósitos aluvionares recentes situam-se no Córrego do Fogo e ribeirões Santana, Soturno e Setubinha, sendo mais desenvolvidos nas cabeceiras do Córrego do Fogo e ao longo de todo o percurso dos ribeirões Santana e Soturno.

O único depósito de tálus observado encontra-se próximo à margem esquerda do Córrego do Fogo, cerca de $4 \mathrm{~km}$ a montante de sua foz. 


\section{Depósitos Paleoaluvionares}

A base dos depósitos paleoaluvionares do Ribeirão Setubinha está disposta cerca de 5 a 8 metros acima do nível atual da drenagem. Estes depósitos são compostos essencialmente por duas sequências, uma superior, de composição argilosa e outra, inferior, constituída por blocos e seixos rolados dispostos diretamente sobre saprólito de xisto. A Figura 2 mostra, esquematicamente, as relações entre o paleoalúvio, o alúvio recente e o xisto da Formação Capelinha.

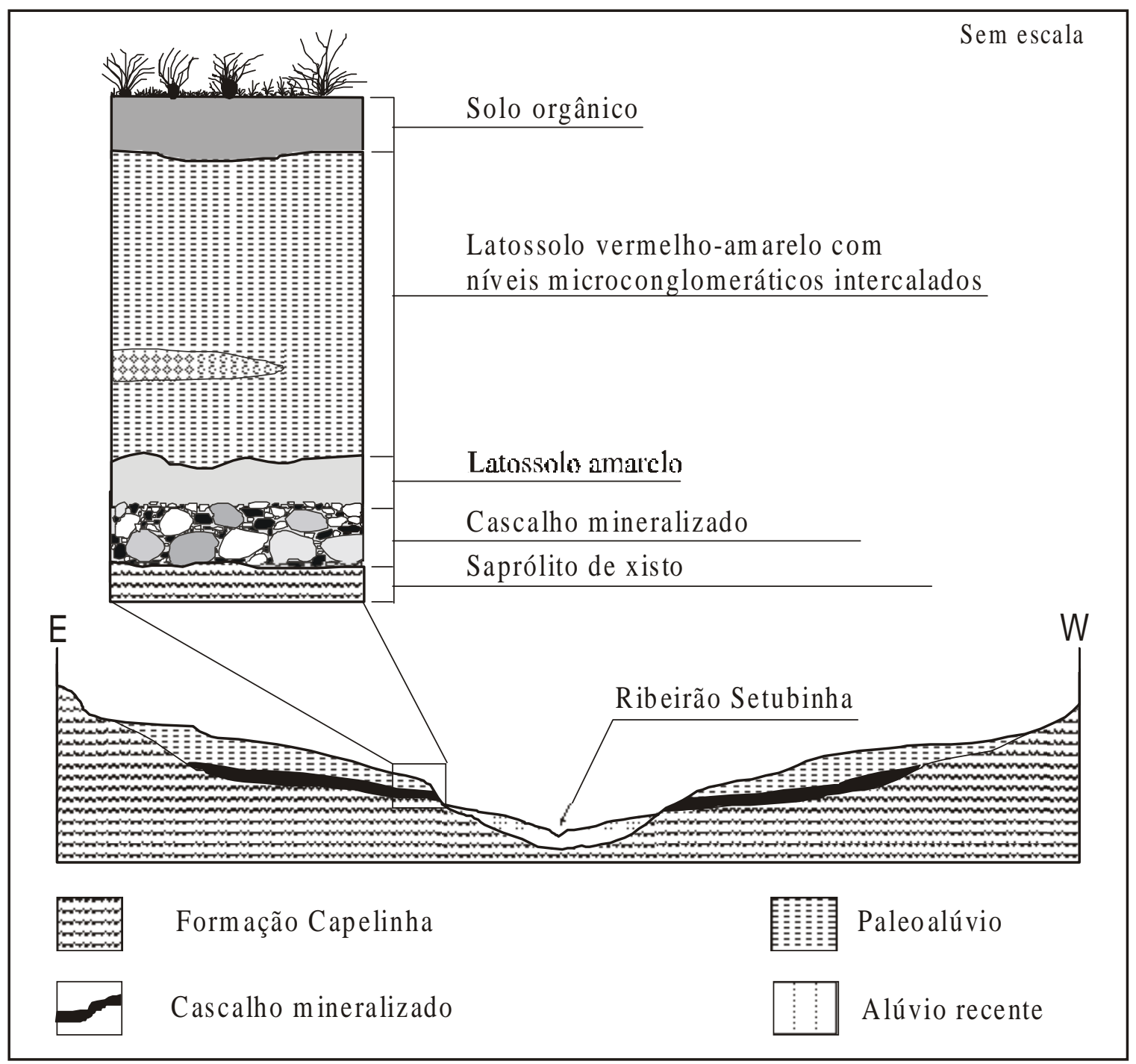

Figura 2: Perfil transversal e seção colunar, esquemáticos, ilustrando a distribuição lateral e o empilhamento entre o paleoaluvião com horizonte de cascalho mineralizado em alexandrita, o aluvião recente e o Ribeirão Setubinha.

Figure 2: Schematic transect and section showing the lateral distribution and the stratigraphic relations shown by an alexandrite deposit in the Setubinha creek.

A Figura 3 apresenta a descrição detalhada de um perfil do paleoaluvião mineralizado do Ribeirão Setubinha.

O nível argiloso varia entre 4 e $8 \mathrm{~m}$ de espessura e mostra-se estruturado pedologicamente. Sua análise morfológica evidencia um latossolo vermelho-amarelo. Sua composição argilosa é homogênea, não obstante a presença localizada de níveis arenosos, mais raramente portador de pequenos seixos e grânulos intercalados. Uma linha de seixos centimétricos está presente localmente.

Subjacente ao nível siltoargiloso encontra-se, em contato abrupto, o leito de cascalho portador de alexandrita. Trata-se de um nível de cerca de $1 \mathrm{~m}$ a 1,5 $\mathrm{m}$ de espessura, composto essencialmente por seixos e matacões de quartzo de veio, quartzito de granulação grossa e localmente, grandes fragmentos de pegmatito gráfico. Os blocos de quartzo apresentam-se maiores e mais bem arredondados que os fragmentos de quartzito. Este nível de cascalho é extremamente mal selecionado. Nele predominam os seixos e matacões, que podem medir mais de $1 \mathrm{~m}$ em seu maior diâmetro. Fragmentos de alexandrita, medindo poucos milímetros, ocorrem associados a esta fração grossa. 


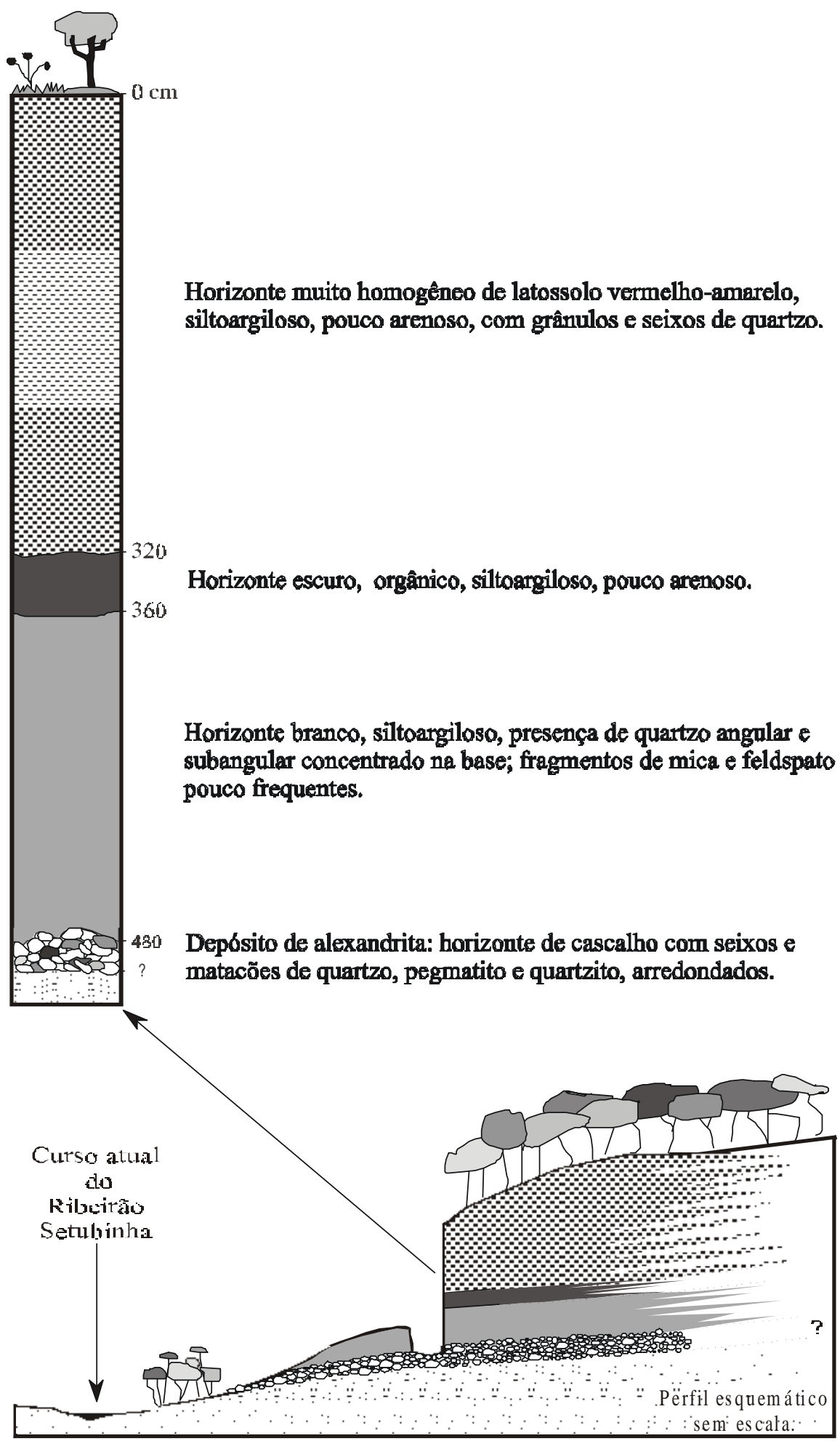

Figura 3: Perfil geral de paleoaluvião do Ribeirão Setubinha, com destaque para a seção colunar detalhada do corte de um garimpo de alexandrita.

Figure 3: Stratigraphic section for an alexandrite deposit in Setubinha creek.

\section{Depósitos Aluvionares Recentes}

Os vales da maioria das drenagens da área garimpeira são amplos e parcialmente entulhados por sedimentos aluvionares. Os rios estão, atualmente, reescavando este material aluvionar.

A espessura deste tipo de depósito varia muito em função da sua localização ao longo do rio. Nos depósitos à montante a cobertura atinge cerca de $10 \mathrm{a} 15 \mathrm{~m}$ acima do nível atual da drenagem. Já nas partes mais baixas, principalmente no Ribeirão Setubinha, a cobertura atinge 1,5 $\mathrm{m}$ acima do nível da lâmina d'água. A camada mineralizada, entretanto, encontra-se cerca de 3 metros, em média, abaixo do nível freático, independentemente 
da espessura da cobertura sobrejacente.

A Figura 4 apresenta a descrição morfológica de um perfil de detalhe realizado no garimpo do "Seu"
Alípio, localizado na nascente do Córrego do Fogo. A Figura 5 ilustra a posição deste perfil, na estruturação atual da drenagem.

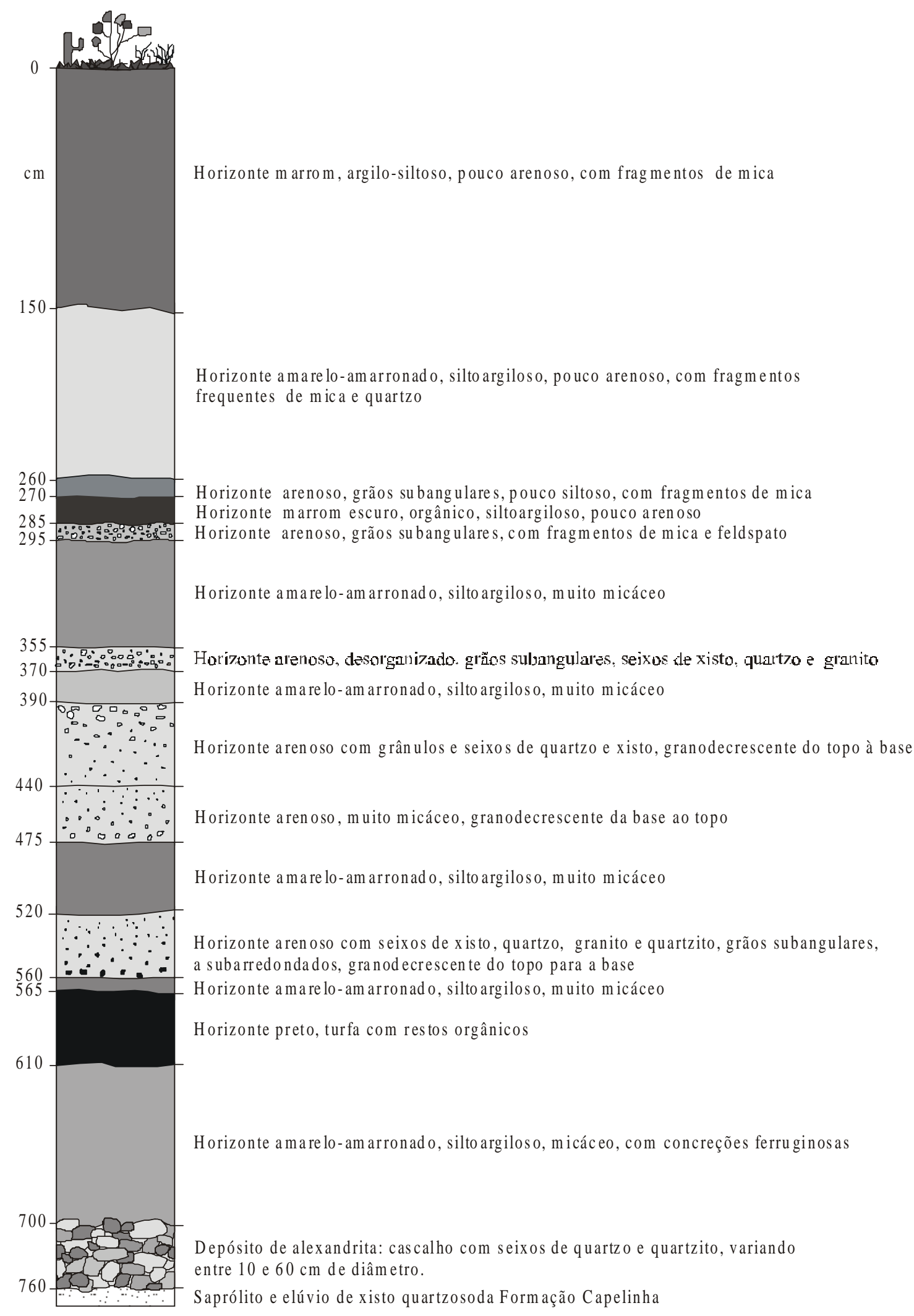

Figura 4. Seção colunar levantada em aluvião recente localizado na nascente do Córrego do Fogo (garimpo do "Seu Alípio").

Figure 4. Stratigraphic section of the alexandrite deposit in the Alípio mine, Córrego do Fogo area. 
Estes alúvios são compostos por uma alternância de níveis centimétricos a métricos de areia (variando de grossa a fina) e argila. A base desta sequência é geralmente argilosa e recobre um nível de cascalho portador de alexandrita.

Este nível de cascalho é composto essencialmente por seixos a matacões de quartzo e quartzito. Sua espessura média é de $1 \mathrm{~m}$. Os clastos possuem forma arredondada e seu eixo maior nunca ultrapassa $60 \mathrm{~cm}$. O contato basal deste horizonte é feito diretamente com o xisto quartzoso saprolitizado da Formação Capelinha.

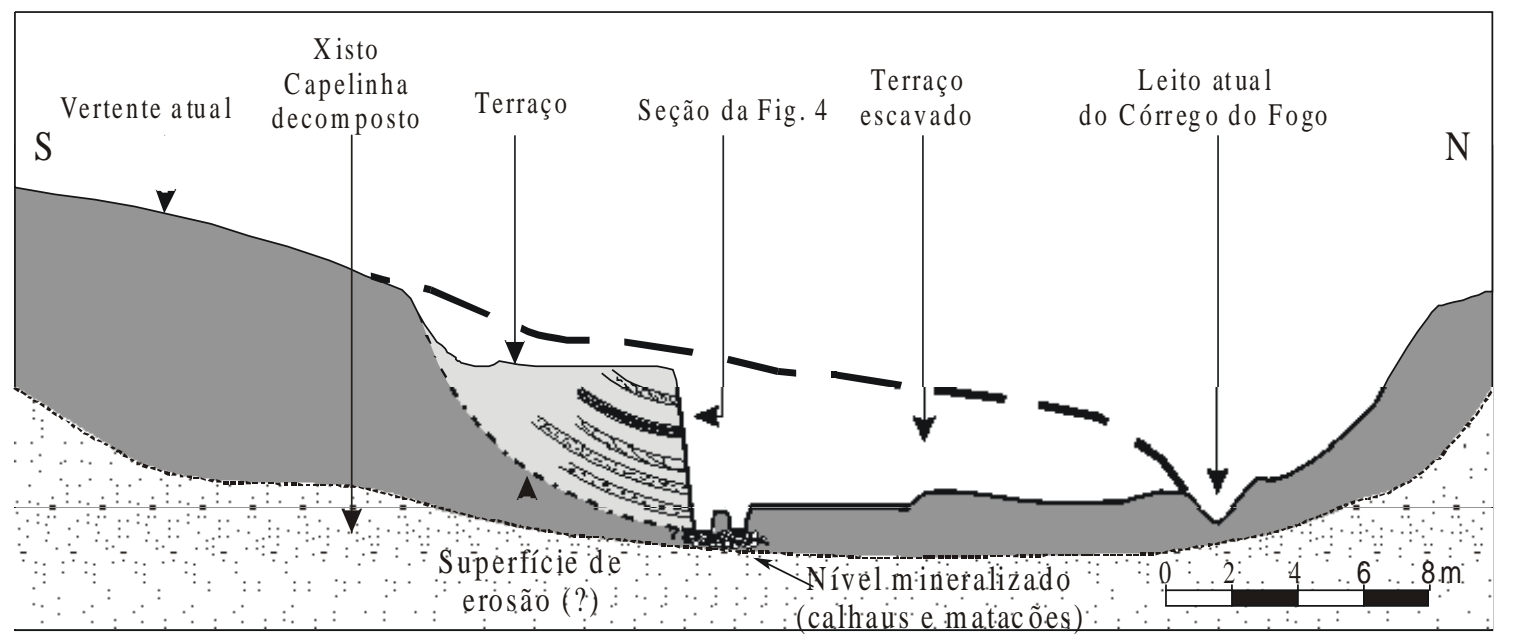

Figura 5: Representação esquemática, em perfil, do posicionamento relativo entre o aluvião recente (seção colunar da Figura 4) e o Córrego do Fogo.

Figure 5: Schematic section showing the relations between the recent alluvium (Fig. 4) and the alexandritebearing layer in the Córrego do Fogo area.

\section{Depósito de Tálus}

Somente um depósito do tipo tálus foi identificado na área estudada. Trata-se de um depósito à meia encosta, próximo à margem esquerda do Córrego do Fogo, cerca de $4 \mathrm{~km}$ antes da sua confluência com o Ribeirão Setubinha.

Este depósito, atualmente um garimpo abandonado, localiza-se cerca de 25 a $30 \mathrm{~m}$ acima do leito do Córrego do Fogo e é composto essencialmente por material argiloso a arenoso, envolvendo fragmentos angulosos de granito, profundamente intemperizados.

Aparentemente, toda a fonte que forneceu material para este depósito foi erodida ou completamente intemperizada, uma vez que o depósito está muito próximo ao topo atual da elevação e não se observam afloramentos de rocha fresca em sua porção superior.

\section{CONCLUSÃO}

O controle dos depósitos da alexandrita de Malacacheta decorre de processos eminentemente aluvionares, desenvolvidos durante o evento erosivo anterior ao atual. O caráter grosseiro do cascalho com presença de matacões sugere que a sedimentação foi dominada por processos torrenciais. Neste evento foi depositado o nível de cascalho com matacões dos paleoaluviões mineralizados em alexandrita. Este nível foi, posteriormente, recoberto por uma espessa sequência de material areno-argiloso, evidenciando estágio em que processos coluvionares e eluvionares predominaram. O depósito de tálus parece ser contemporâneo ao final do processo erosivo gerador dos paleoalúvios mineralizados. A alexandrita presente nos aluviões atuais é atribuída ao retrabalhamento destes paleoalúvios.

Não há consenso sobre a origem do crisoberilo, pois os autores oscilam entre processos pegmatíticos e metamórficos (e.g., Franz e Morteani 1984, Soman e Nair 1985, Martin-Izard et al. 1996).

Entretanto, na maioria dos trabalhos sobre depósitos de alexandrita descrevem-se ambientes geológicos similares, nos quais se encontram rochas metamórficas de médio a alto grau, granitos e rochas ultramáficas, mas pegmatitos nem sempre estão presentes (e.g., Metson e Taylor 1977, Munasingue e Dissanayake 1981, Ustinov e Chizhik 1994, Franz et al. 1996, Bevan e Downes 1997).

Estes ambientes contêm as fontes geoquimicamente contrastantes de elementos que precisam interagir para que ocorra a gênese da alexandrita, i.e., granito como fonte de berílio e rocha ultramáfica como fonte de cromo. Além disso, o ambiente deve ser subsaturado em sílica, ou supersaturado em alumina, pois a alexandrita é um óxido de alumínio e berílio.

No Distrito Gemológico de Malacacheta esta convergência incomum de condições geológicas aconteceu, há cerca de $535 \mathrm{Ma}$, quando o Granito Córrego do Fogo intrudiu a pilha de metassedimentos 
aluminosos com lascas de rochas metaultramáficas. Considera-se que o cromo, detectado no estudo da alexandrita, é oriundo das rochas metaultramáficas, enquanto o berílio provém do granito intrusivo. Os metassedimentos regionais, hospedeiros destas fontes geoquímicas, são portadores de camadas de xistos peraluminosos que permitiram ao sistema manter-se supersaturado em alumina. Um contato entre rocha ultramáfica e xisto peraluminoso poderia se converter em sistema hidrotermal, capaz de cristalizar alexandrita, ao receber fluidos ricos em berílio emanados do granito intrusivo. A rocha-fonte da alexandrita poderia ser um xisto ultramáfico (e.g., anfibólio-flogopita xisto). Enfatiza-se, entretanto, que por ser desconhecida a rocha-fonte da alexandrita de Malacacheta, a interpretação acima é apenas uma atraente hipótese de trabalho.

Contudo, se a alexandrita se cristalizou em sistema espacialmente associado à cúpula do granito, então sua rocha-fonte parece ter sido erodida, uma vez que os principais depósitos desta gema ocorrem em paleoalúvios que cobrem superfícies de erosão que cortam profundamente as rochas da área.

\section{AGRADECIMENTOS}

Nossa especial gratidão aos colegas Vítor Brugnara Pimenta e Eliane Voll pela inestimada contribuição nas discussões e trabalhos de campo. À FAPEMIG (projetos "Potencial Econômico do Complexo Guanhães" coordenado pela Profa. Lydia Lobato e "Transectos Geoeconômicos do Nordeste Mineiro" coordenado por A. C. Pedrosa Soares), e aos programa de pós-graduação da UFOP e UFMG pelo suporte financeiro. Ao Prof. Marcelo A. Martins Neto pela revisão do artigo.

\section{REFERÊNCIAS BIBLIOGRÁFICAS}

Basílio, M.S. 1999. A Alexandrita de Malacacheta, Norte de Minas Gerais. DEGEO/UFOP. Ouro Preto. 111 p. (Dissertação de Mestrado)

Bevan, A.; Downes, P. 1997. Alexandrite chrysoberyl from Dowerin, Western Australia: revisited. Australian Gemmologist 19: 464465

Cassedanne, J.P.; Baptista, N.R. 1984. Étude de quelques alluvions à crysobéryl. Anais Acad. Bras. Ciências 56(3): 256-281

Franz, G.; Morteani, G. 1984. The formation of chrysoberyl in metamorphosed pegmatites. Journal of Petrology 25(1): 27-52
Franz, G.; Gilg, H.A., Grundmann, G.; Morteani, G. 1996. Metassomatism at a granitic pegmatite-dunit contact in Galicia: the Franquira occurrence of chrysoberil (alexandrite), emerald, and phenakite: discussion. Canadian Mineralogist 34: 13291331

Gübelin, E.; Schmetzer, K. 1982. Gemstones with alexandrite effect. Gems and Gemology 18(4): 197-203

Guimarães, M.L.V.; Grosi-Sad, J.H. 1997. Geologia da Folha Malacacheta, Minas Gerais. Projeto Espinhaço, UFMG/ COMIG. 67p.

Henn, U. 1987. Inclusions in yellow chrysoberyl e alexandrite. Australian Gemmologist 16(6): 217-220

Martin-Izard, A.; Paniagua, A.; Moreiras, D.; Acevedo, R.D.; Marcos-Pascual, C. 1996. Metassomatism at a granitic pegmatite-dunit contact in Galicia: the Franqueira ocorrence of chrysoberil (alexandrite), emerald, and phenakite: Reply. Canadian Mineralogist 34: 1332-1336

Metson, N.A.; Taylor, A.M. 1977. Observations on some Rhodesian emerald occurrences. Journal of Gemmology 15: 422-434

Munasinghe, T.; Dissanayake, C.B. 1981. The origin of gemstones of Sri Lanka. Economic Geology 76: 1216-1225

Pedrosa Soares, A.C. 1995. Potencial aurífero do Vale do Araçuaí, MG: História da Exploração, geologia e controle tectonometamórfico. IG-UnB. Brasília. 177 p. (Tese de Doutorado).

Pedrosa-Soares, A.C.; Dardene, M.A.; Hasui, Y.; Castro, F.D.C.; Carvalho, M.V.A. 1994. Nota Explicativa dos Mapas Geológico, Metalogenético e de Ocorrências Minerais do Estado de Minas Gerais. Belo Horizonte, COMIG, 97 p.

Pedrosa-Soares, A.C.; Wiedemann-Leonardos, C.M. 2000. Evolution of the Araçuaí Belt and its connection to the Ribeira Belt, Eastern Brazil. In: U.G. Cordani, E.J. Milani, A. Thomaz-Filho, D.A. Campos (eds), Tectonic Evolution of South America. Rio de Janeiro, IGC Brazil 2000, 265-285

Pinheiro, M.V.B.; Basílio, M.S.; Krambrock, K.; Dantas, M.S.S.; Paniago, R.; Assunção, A.L.; Pedrosa-Soares, A.C. 2000. The cause of color of the blue alexandrites from Malacacheta, Minas Gerais, Brazil. Journal of Gemmology 27(3): 161-170

Pinto, C.P.; Pedrosa-Soares, A.C. 2001. Brazilian Gem Provinces. Australian Gemmologist 21(1): 12-16

Proctor, K. 1988. Chrysoberil and alexandrite from the pegmatite districts of Minas Gerais, Brasil. Gems and Gemology 24(1): 1-32

Schmetzer, K.; Bank, H.; Gübelin, E. 1980. The alexandrite effect in minerals: Chrysoberyl, Garnet, Corundum, Fluorite. N. Jb. Miner. Abh. 138(2): 147-164

Soman, K.; Nair, N.G.K. 1985. Genesis of chrysoberyl in the pegmatites of southern Kerala, Índia. Mineralogical Magazine 49(5): 733-738

Ustinov, V.I.; Chizhik, O. 1994. Sequential nature of the formation of emerald and alexandrite in micaite-type deposits. Geochemistry International 31(7): 115-118

Voll, E.; Pimenta, V.B. 1997. Mapeamento geológico da área garimpeira de alexandrita entre Setubinha e Malacacheta, MG. Trabalho Geológico de Graduação, IGC-UFMG, 52 p.

White, W.B.; Roy, R.R.; Crichton, J.M. 1967. The "alexandrite effect": an optical study. Americam Mineralogist 52: 861-871 